\title{
Synthesis and Properties of Segmented Block Poly(oxyethylene-block-esteramide)
}

\author{
Sang-Il Han, Seung Soon IM, ${ }^{\dagger}$ Dong Kuk KIM, ${ }^{*}$ and Young Tae YoO** \\ Department of Textile \& Polymer Engineering, College of Engineering, Hanyang University, \\ 17 Haengdang-dong, Seongdong-gu, Seoul 133-791, Korea \\ *Department of Chemistry, Hanyang University, Ansan 425-791, Korea \\ ${ }^{* *}$ Department of Industrial Chemistry, College of Engineering, Konkuk University, \\ 93-1 Mojin-dong, Kwangjin-ku, Seoul 143-701, Korea
}

(Received May 20, 2002; Accepted October 22, 2002)

\begin{abstract}
A series of poly(oxyethylene-block-esteramide)s (PASHs) containing $p$-aminobenzoic acid units were prepared by bulk polymerization of $N, N^{\prime}$-bis ( $p$-ethoxycarbonylphenyl) sebacamide and mixed diols of 1,6-hexanediol and poly(ethylene glycol) (PEG, MW 600, up to $34 \mathrm{~mol} \%$ ). The poly(oxyethylene-block-esteramide)s exhibited the inherent viscosity ranging from 0.61 to $0.87 \mathrm{dL} \mathrm{g}^{-1}$ while the parent poly(ester-amide) yielded an inherent viscosity of $0.41 \mathrm{dL} \mathrm{g}^{-1}$, which is attributable to chain extension and homogeneity of reaction mixture in the presence of PEG. The parent poly(ester-amide) showed relatively fast crystallization and high $T_{\mathrm{g}}$ for its alternating arrangement of esteramide sequence, resulting in extremely brittle characteristics. However, the glass transition temperatures, $T_{\mathrm{g}}$, of the poly(oxyethylene-block-esteramide)s containing $13-16 \mathrm{~mol} \%$ of PEG were found in the range $31-45^{\circ} \mathrm{C}$ and demonstrated greatly improved mechanical properties. The storage modulus in ambient temperature was ca. 1300-1400 MPa, and the tensile strength was measured $40-85 \mathrm{MPa}$. From the dynamic mechanical analysis it was also found that storage modulus at rubbery plateau region increased as PEG was introduced up to $16 \mathrm{~mol} \%$, indicating a good dimensional stability above $T_{\mathrm{g}}$.

KEY WORDS Poly(ester-amide) / Poly(oxyethylene-block-esteramide)s / Hard Segment / Soft Segment / Dimensional Stability / Dynamic Mechanical Properties /
\end{abstract}

There has been growing interest in aromatic poly(ester-amide)s as a new series of thermoplastic materials. ${ }^{1,2}$ Among many structural features of poly(ester-amide)s, the distribution of amide and ester segments is one of the most critical factors determining the physical properties. ${ }^{3-5}$ Recently, alternating poly(ester-amide)s have been synthesized to implement structural regularity to the random poly(esteramide)s. ${ }^{6,7}$ Van Benekom et al. reported that alternating poly(ester-amide)s derived from bisesteramide (1,4-buthylene terephthalamide dimethyl ester (T4Tdimethyl)) demonstrated rapid crystallization rate and high dimensional stability. ${ }^{8}$ However, these alternating poly(ester-amide)s are very brittle for practical use. To overcome these shortcomings, new type of aromatic poly(ester-amide)s was developed by introducing flexible spacers comprising aliphatic polyesters or polyethers. Conventionally, it was well recognized that the molecular weight, crystallinity and mechanical property of these copolymers depends on compatibility and composition between the hard phase and the soft phase. Niesten synthesized poly(ester-amide)s from 1,4-phenylene terephthalamide dimethyl ester (TФTdimethyl) and poly(tetramethylene oxide) (PTMO) as a soft phase. ${ }^{10}$ A major disadvantage of TФТ-РТМО copolymers system was that the polymerization was conducted in the presence of NMP, since TФT-dimethyl is poorly soluble in the reaction mixture at the polymerization temperature.

In this present study, we prepared the segmented poly(oxyethylene-block-esteramide)s employing $N, N^{\prime}$ bis( $p$-ethoxycarbonylphenyl) sebacamide and PEG via bulk polymerization route. The solvent-free melt polymerization is preferred since no post-treatment is necessary after the reaction. It was anticipated that $N, N^{\prime}$-bis( $p$-ethoxycarbonylphenyl) sebacamide inherently provides alternating arrangement of amide and ester groups, while PEG segments serve as a reaction medium as well as a flexible spacer. The compatibility of $N, N^{\prime}$-bis ( $p$-ethoxycarbonylphenyl) sebacamide and PEG should favorably affect the synthesis. The effects of PEG content on the thermal and physicochemical properties of resulting copolymers were investigated.

\section{EXPERIMENTAL}

\section{Materials}

Ethyl 4-aminobenzoate (Aldrich Chem. Co), 1,6hexanediol (Aldrich Chem. Co), and poly(ethylene gly-

${ }^{\dagger}$ To whom correspondence should be addressed (Fax: +82-2-2297-5859, E-mail: imss007@hanyang.ac.kr). 


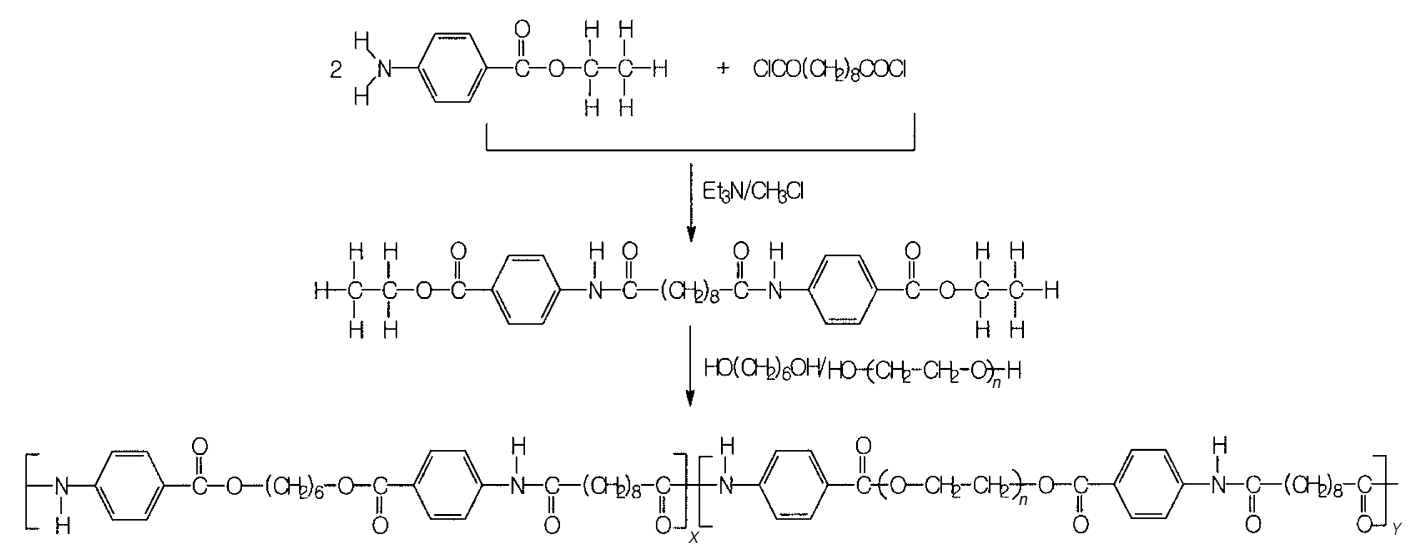

Scheme 1. Synthesis of poly(oxyethylene-block-esteramide)s by melt condensation.

col) $\left(M_{\mathrm{w}} 600\right)$ (Yakuri Pure Chem. Co) were used without further purification. Triethylamine (Aldrich Chem. Co) was distilled over calcium hydride under a nitrogen atmosphere. Sebacoyl chloride (Aldrich Chem. Co) was used after vacuum distillation.

\section{Polymerization}

Poly(oxyethylene-block-esteramide)s (PASH) were synthesized via melt polycondensation and esterification steps as given in Scheme 1. $N, N^{\prime}-\operatorname{Bis}(p-$ ethoxycarbonylphenyl) sebacamide was synthesized from ethyl 4-aminobenzoate and sebacoyl chloride according to the procedure previously reported. ${ }^{11}$ Polymerization was performed using antimony(III) oxide as a catalyst via two step reaction. A mixture of $10 \mathrm{mmol}(5 \mathrm{~g})$ of $N, N^{\prime}$-bis( $p$-ethoxycarbonylphenyl) sebacamide and $12 \mathrm{mmol}$ (1.4 g) of 1,6-hexanediol with $\operatorname{PEG}\left(M_{\mathrm{W}} 600,0-3 \mathrm{mmol}\right)$ were placed in a four-necked $50 \mathrm{~mL}$ flask equipped with a nitrogen inlet, condenser, and an overhead stirrer. Excess diols was used to control stoichiometry at $260^{\circ} \mathrm{C}$ under vacuum, as well as to form ester linkage by esterification reaction with $N, N^{\prime}$ bis ( $p$-ethoxycarbonylphenyl) sebacamide. Bath temperature was allowed to increase to $100^{\circ} \mathrm{C}$ and maintained at the temperature for $20 \mathrm{~min}$. Antimony(III) oxide was introduced when all the reaction mixture was melted. The reaction mixture was heated to $200^{\circ} \mathrm{C}$ for $20 \mathrm{~h}$ under a nitrogen atmosphere. Ethanol was distilled off in the process. Then, nitrogen supply was disconnected and the reactor was connected to a vacuum pump with a pressure gage. The reactor temperature was gradually increased to $260^{\circ} \mathrm{C}$ and maintained for $5-6 \mathrm{~h}$ in a vacuum of $<0.1$ torr. The synthesized polymer was dissolved in hot $N, N^{\prime}$-dimethyl acetamide, then precipitated from water. The product was collected by filtration and dried under reduced pressure at $40{ }^{\circ} \mathrm{C}$ to give a yellow powdery material.
Copolymers are coded with the initials of starting materials. The numbers at the end of these codes denote the contents of poly(ethylene glycol). For instance, a poly(oxyethylene-block-esteramide) derived from the components of ethyl 4-aminobenzoate, sebacoyl chloride, 1, 6-hexanediol, and PEG ( $7 \mathrm{~mol} \%$ of mixed diol) is denoted as PASH-7.

\section{Polymer Characterization}

The copolymer composition was confirmed using $400 \mathrm{MHz}{ }^{1} \mathrm{H}$ NMR (Bruker) after the samples were dissolved in deuterated trifluoroacetic acid without an internal standard or deuterated dimethyl sulfoxide containing TMS. Inherent viscosity was determined by measurement using a Cannon-Ubbelhode microviscometer at the concentration of $0.3 \mathrm{~g} \mathrm{dL}^{-1}$ in $N, N^{\prime}-$ dimethyl acetamide at $25^{\circ} \mathrm{C} \pm 0.1{ }^{\circ} \mathrm{C}$. Samples for the analysis (DSC, DMA, WAXD, tensile test) were prepared on the compress mould machine. The temperature setting was $30-50{ }^{\circ} \mathrm{C}$ above $T_{\mathrm{m}}$. After melting, samples were quenched to ice water. Before use, all polymers were dried in a vacuum oven at $40^{\circ} \mathrm{C}$ for $48 \mathrm{~h}$. The melting behaviors of PASH series were studied using a Perkin-Elmer DSC-7, which was precalibrated with Indium and Zinc standards. Upon melting, the samples were heated to $250^{\circ} \mathrm{C}$ at a rate of $10^{\circ} \mathrm{C} \mathrm{min}^{-1}$. The peak point of the melting peak was taken as the melting temperature. The micro-structural changes were investigated by wide angle X-Ray diffraction (WAXD). Spectra were taken at room temperature by a scan speed of $10^{\circ} \mathrm{min}^{-1}$ over the range of $5^{\circ}$ to $40^{\circ}$ using an X-Ray diffractometer equipped with a Nickel filtered $\mathrm{Cu}-K \alpha$ radiation. ( $40 \mathrm{kV}, 30 \mathrm{~mA}$ ) (Rigaku Denki, Model DMAX 2000). Morphology of spherullites was observed under a polarizing optical microscope (Nikon HFX-11A). The storage and loss moduli were measured as a function of temperature by dynamic mechanical analysis (TA-DMA 2980) at a frequency of $1 \mathrm{~Hz}$ 

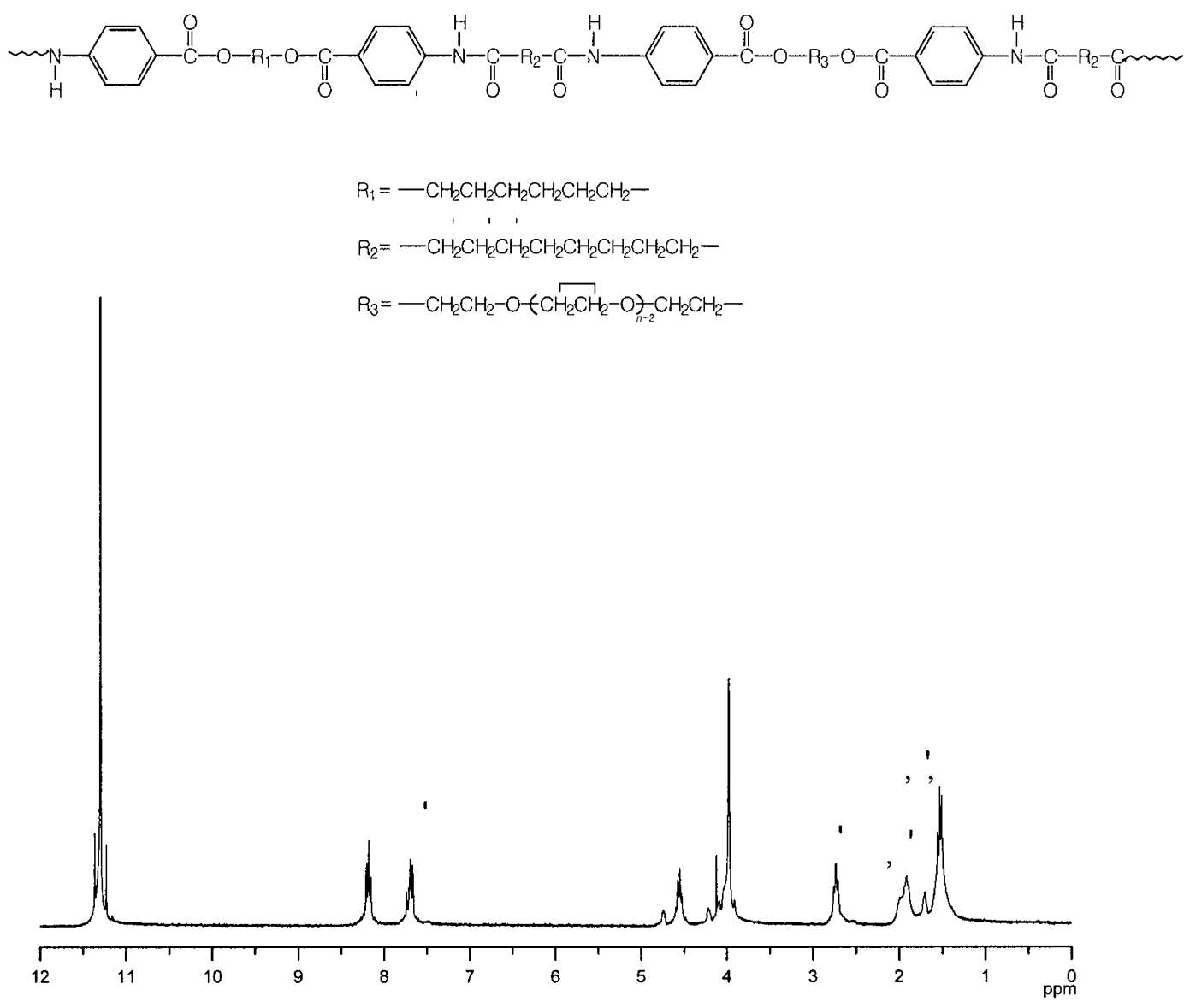

Figure 1. The ${ }^{1} \mathrm{H}$ NMR spectra of PASH-26, poly(oxyethylene-block-esteramide).

Table I. Polymerization data and thermal properties of PASHs

\begin{tabular}{|c|c|c|c|c|c|c|c|c|}
\hline \multirow[b]{2}{*}{$\begin{array}{c}\text { Polymer } \\
\text { Code }\end{array}$} & \multicolumn{2}{|c|}{ Composition } & \multirow{2}{*}{$\frac{\text { Yield }}{\%}$} & \multirow{2}{*}{$\frac{\eta_{\text {inh }^{\mathrm{c}}}}{\mathrm{dL} \mathrm{g}^{-1}}$} & \multirow{2}{*}{$\frac{T_{\mathrm{m}}}{{ }^{\circ} \mathrm{C}}$} & \multirow{2}{*}{$\frac{\Delta H_{\mathrm{f}}}{\mathrm{Jg}^{-1}}$} & \multirow{2}{*}{$\frac{T_{\mathrm{c}}^{\mathrm{d}}}{{ }^{\circ} \mathrm{C}}$} & \multirow{2}{*}{$\frac{T_{\mathrm{m}}-T_{\mathrm{c}}{ }^{\mathrm{d}}}{{ }^{\circ} \mathrm{C}}$} \\
\hline & $\begin{array}{l}\text { Monomer } \\
\text { mol ratio }^{\mathrm{a}}\end{array}$ & $\frac{\mathrm{H} \cdot \mathrm{D}: \mathrm{PEG}}{\mathrm{mol} \%^{\mathrm{b}}}$ & & & & & & \\
\hline PASH-0 & $1 / 1.2 / 0$ & $100: 0$ & 85 & 0.47 & 221.3 & 50.6 & 203.3 & 18.0 \\
\hline PASH-7 & $1 / 1.2 / 0.05$ & $92: 7$ & 92 & 0.64 & 214.1 & 39.3 & 190.5 & 23.6 \\
\hline PASH-13 & $1 / 1.2 / 0.10$ & $87: 13$ & 87 & 0.63 & 208.9 & 38.7 & 180.7 & 28.2 \\
\hline PASH-16 & $1 / 1.2 / 0.16$ & $84: 16$ & 80 & 0.61 & 207.1 & 37.7 & 179.9 & 27.2 \\
\hline PASH-26 & $1 / 1.2 / 0.21$ & $74: 26$ & 85 & 0.66 & 166.0 & 11.6 & 127.4 & 38.6 \\
\hline PASH-34 & $1 / 1.2 / 0.30$ & $66: 34$ & 78 & 0.87 & $165.0 / 176.0$ & 23.2 & 152.2 & 23.8 \\
\hline
\end{tabular}

${ }^{\text {a}}$ Feed molar ratio of monomers; $\left(N, N^{\prime}\right.$-bis $(p$-ethoxycarbonyl/phenyl)sebacamide/1,6-hexanediol/poly(ethylene glycol)). ${ }^{\mathrm{b}} \mathrm{Calculated}$ molar ratios of H·D (1,6-hexanediol) : PEG (poly(ethylene glycol)) determined by ${ }^{1} \mathrm{H}$ NMR. ${ }^{c}$ Inherent viscosity in $N, N$-dimethyl acetamide at $25^{\circ} \mathrm{C} \pm 0.1^{\circ} \mathrm{C}, 0.3 \mathrm{~g} \mathrm{dL}^{-1}$. ${ }^{\mathrm{d}}$ Obtained as crystallization temperature on cooling scan at $10^{\circ} \mathrm{C} \mathrm{min}^{-1}$ after melting.

under nitrogen atmosphere. Samples were quenched to $-40^{\circ} \mathrm{C}$ and then gradually heated to $180^{\circ} \mathrm{C}$ at a rate of $2{ }^{\circ} \mathrm{C} \mathrm{min}^{-1}$. The peak position of loss modulus is taken as a glass transition temperature. The films were prepared by compressing the polymer melt between Teflon ${ }^{\circledR}$ sheet and subsequent quenching in water. Mechanical properties were measured on a TA 4465 instruments with $1 \mathrm{kN}$ load cell at the cross head speed of $10 \mathrm{~mm} \mathrm{~min}^{-1}$. The polymer films were prepared on the film with a dimension of $5 \mathrm{~mm}$ width, $15 \mathrm{~mm}$ gauge length, and $0.1-0.2 \mathrm{~mm}$ thickness.

\section{RESULTS AND DISCUSSION}

Figure 1 shows a representative ${ }^{1} \mathrm{H}$ NMR spectrum of PASH-26. The integration ratios between the peaks at $4.55 \mathrm{ppm}\left(-\mathrm{C}_{2}-\mathrm{OCO}-\right)$ and $3.98 \mathrm{ppm}(-\mathrm{O}-$ $\left.\left(\mathrm{C}_{2}{ }_{2} \underline{\mathrm{C}}_{2} \mathrm{O}-\right)_{n-2}\right)$ were used to determine the compositions of 1, 6-hexanediol and of PEG in the copolymer. The feed and observed compositions of respective monomer are presented in Table I. ${ }^{1} \mathrm{H}$ NMR study indicates that the copolymers contain less amounts of 


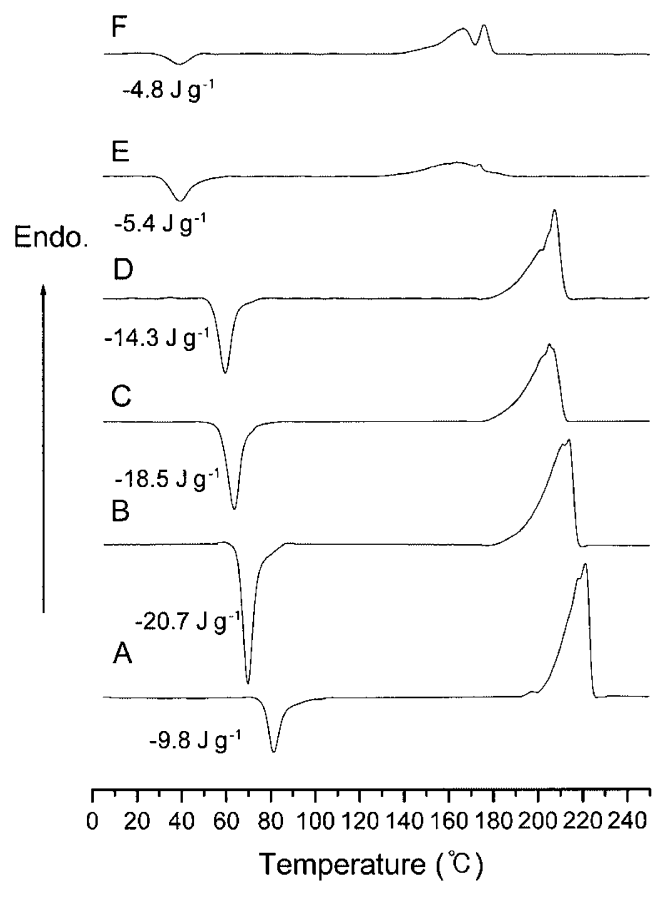

Figure 2. DSC traces for PASHs in first heating run at $10{ }^{\circ} \mathrm{C} \mathrm{min}^{-1}$; A, PASH-0; B, PASH-7; C, PASH-13; D, PASH-16; E, PASH-26; F, PASH-34.

hexane diol than the corresponding feed compositions due to the higher volatility than PEG. The inherent viscosity, $\eta_{\text {inh }}$, of PASHs containing PEG measured in the range of 0.61 to $0.87 \mathrm{dL} \mathrm{g}^{-1}$. The $\eta_{\text {inh }}$ value consistently increased with the incorporation of PEG segments.

Figure 2 shows the DSC thermograms of PASH series. The melting endotherms of these poly(oxyethylene-block-esteramide)s shifted to lower temperatures as the PEG content increases. The PASH- 0 without PEG has an exotherm peak with relatively lower intensity. This result may be due to the relatively dominant crystallization rate of alternating poly(esteramide), PASH-0. The crystallization peak of PASH-7 obtained on heating scan or cooling scan has a sharper crystallization peak than the other PASHs containing PEG. This result, together with the facts that PASH-7 has a lower degree of supercooling $\left(T_{\mathrm{m}}-T_{\mathrm{c}}\right)$ for crystallization, indicates that $7 \%$ of soft segments enhance the crystallization of hard segments more effectively by plasticizing the chains. On the other hand, when the PEG content was $26 \%$ or higher, the melting temperature shifted below $170{ }^{\circ} \mathrm{C}$, displaying the dual melting peaks. The shape of melting endotherms became broader and the crystallinity decreased drastically because of loss of structural order as well as retardation of crystallization by the dilution effect. ${ }^{12}$ Interestingly, PASH-34 showed slightly higher heat of fusion than PASH-26. From the combination of DSC, X-Ray diffraction studies and spherulite morphology, it seems that the crystallization of isolated hard segment is fa-
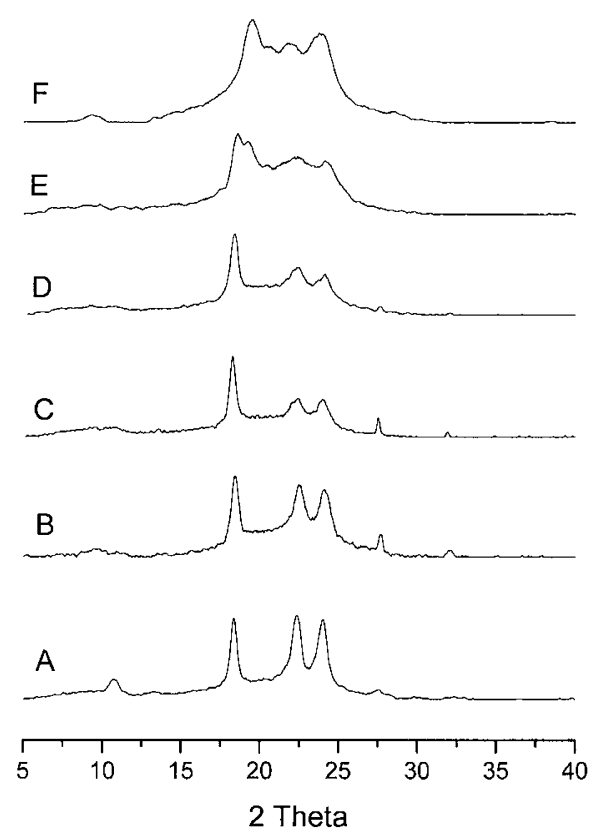

Figure 3. WAXD patterns of PASH films crystallized at ambient temperature; A, PASH-0; B, PASH-7; C, PASH-13; D, PASH16; E, PASH-26; F, PASH-34.

vorably affected in the presence of high content of PEG. Sorta et al. investigated the thermal properties of aromatic poly(ester-amide)s with polyether block and proposed that two melting peaks are due to the melting of isolated segments, which can join in the neighboring hard segments or crystallize in the form of clusters. ${ }^{13}$

$\mathrm{X}$-Ray diffraction patterns for the films crystallized at ambient temperature are depicted as in Figure 3. WAXD pattern of PASH- 0 exhibits distinct crystalline peaks at $18^{\circ}, 22^{\circ}$, and $24^{\circ}$. As PEG content in the segmented block copolymers increased, WAXD curves become only broader without any significant changes. $\mathrm{He}$ and Olley previously reported that the aromatic poly(ester-amide) with flexible spacers showed only minor variations with different crystallization temperature, suggesting that it resulted in the minor modification within one phase. ${ }^{14}$ In this study, in spite of insignificant variations in the WAXD pattern, several features are worth to be noted. WAXD curves of PASH-26 revealed two peaks with an additional peak at $19^{\circ}$. In case of PASH-34, the two peaks are distinctly associated at $19^{\circ}$, indicating that different crystallite could be formed by the introduction of excess PEG.

Figures $4 \mathrm{a}-4 \mathrm{c}$ show the polarizing micrographs of PASHs crystallized for $2 \mathrm{~h}$ at $25^{\circ} \mathrm{C}$ below their melting points. Different kinds of spherulites were observed from the crystallization of PASHs with various compositions. In polyamides, the positive spherulites are usually observed due to the preferred alignment of the hydrogen-bonding direction along the spherullite radii. ${ }^{15}$ PASH-0 showed impinging large spherulites as 
(a)

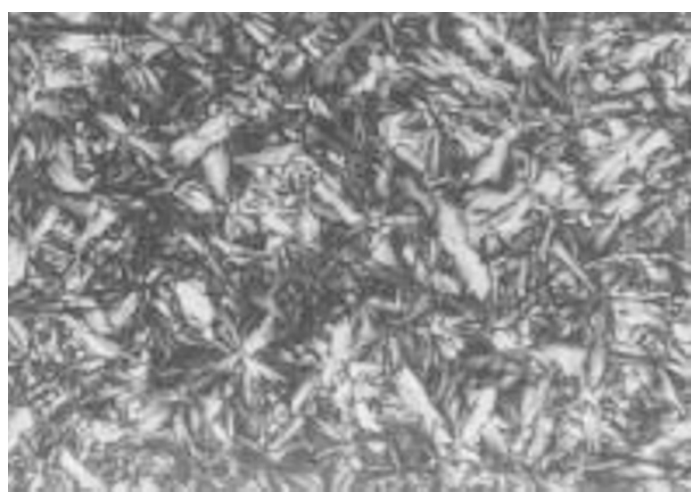

(b)

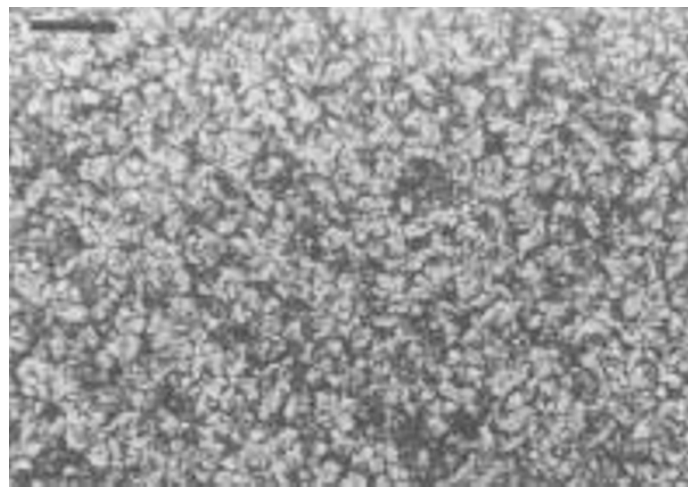

(c)

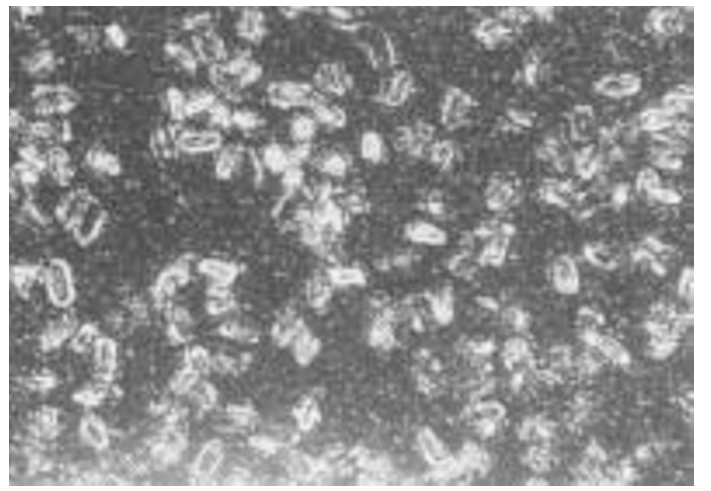

Figure 4. The polarizing optical micrographs of spherulites grown from melts; (a) PASH-0, isothermal crystallization at $200^{\circ} \mathrm{C}$; (b) PASH-16, isothermal crystallization at $180^{\circ} \mathrm{C}$; (c) PASH-34, isothermal crystallization at $140^{\circ} \mathrm{C}$ (scale bar : $\left.50 \mu \mathrm{m}\right)$.

shown in Figure 5a. It is considered to be a characteristic of the lamellar containing rigid $p$-aminobenzoic acid unit, which is likely to orient regularly along radii of spherulite. The spherulites of PASH-16 are smaller than those in the PASH-0. The spherulitic morphology of PASH-34 was observed as an occasional appearance of oval textures with small concentric ring as shown in Figure 4c.

Storage modulus and loss modulus were measured using dynamic mechanical analysis (DMA). For the poly(oxyethylene-block-esteramide) containing less than $13 \mathrm{~mol} \%$ of PEG, the modulus could not be measured because compress molded film was extremely brittle. The PASHs containing $26 \mathrm{~mol} \%$ and (a)

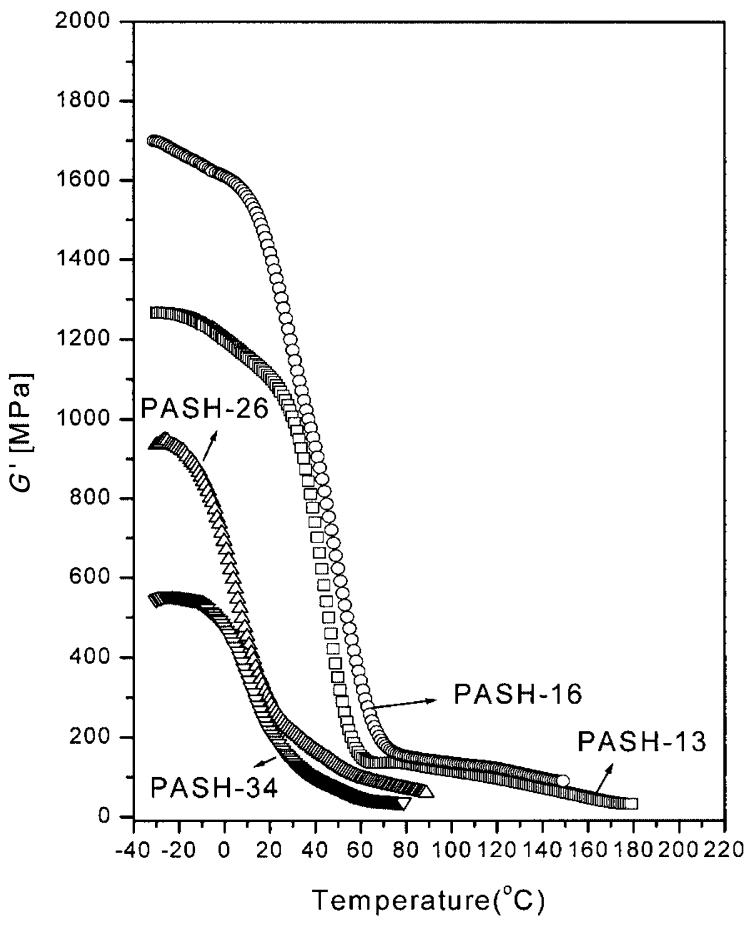

(b)

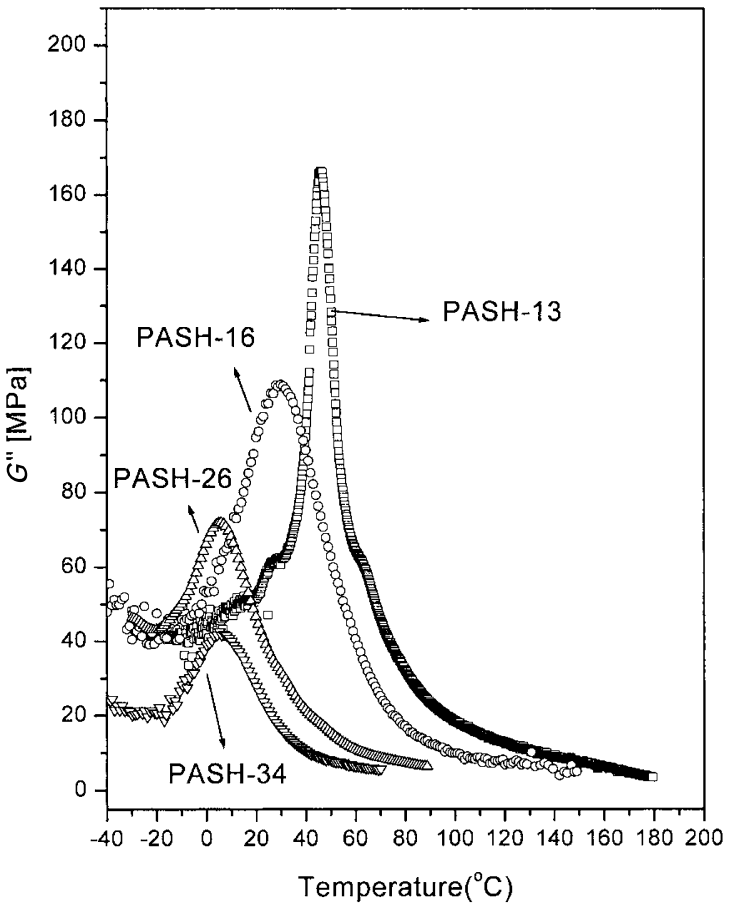

Figure 5. Storage modulus (a) and Loss modulus (b) of PASHs versus the temperature.

$34 \mathrm{~mol} \%$ of PEG were obtained as rubber-like materials with low values (100-200 MPa) of $G^{\prime}$ at ambient temperature. Figure 5a shows the storage modulus of PASHs plotted against the temperature for various PEG contents. PASH-16 has a higher storage modulus compared with PASH-13. A plausible explanation may be that the introduction of 16 mol\% PEG is able to increase the chain mobility, which lead to the increase of crystallinity by the plasticization effect during heating process. The level of the modulus above $T_{\mathrm{g}}$ is im- 
(6a)

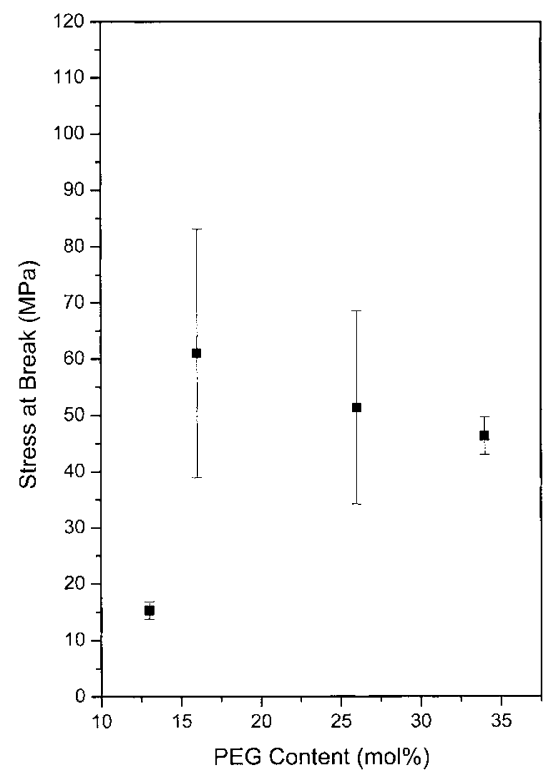

(6b)

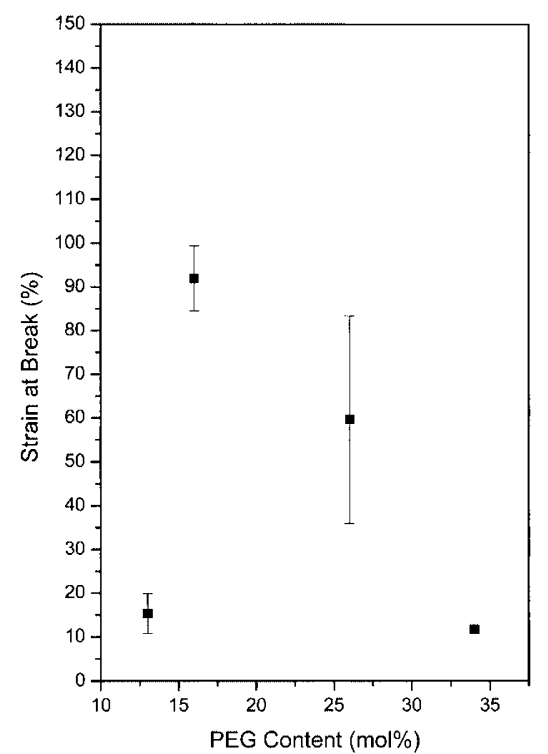

Figure 6. Stress at break (a) and strain at break (b) of PASHs.

portant for high temperature applications. As shown in Figure $5 \mathrm{~b}$, the $T_{\mathrm{g}}$ was taken as maximum of the curve of the loss modulus. $G^{\prime}$ in the rubbery plateau region above $T_{\mathrm{g}}$ is usually measured at $T_{\mathrm{g}}+40^{\circ} \mathrm{C}$. ${ }^{16}$ The decrease of the modulus above $T_{\mathrm{g}}$ is expressed as following eq $1 .^{6}$

$$
\Delta G^{\prime}=\frac{G_{\left(T_{\mathrm{g}}+40\right)}^{\prime}}{G_{\left(T_{\mathrm{fl}}-40\right)}^{\prime}}
$$

The values of $\Delta G^{\prime}$ and $T_{\mathrm{g}} / T_{\mathrm{m}}$ are given in Table II. High values of $\Delta G^{\prime}$ indicate strong decrease of the modulus. In eq $1 T_{\mathrm{fl}}$ is the temperature of flow $\left(G^{\prime}<5 \mathrm{MPa}\right)$ due to a loss of crystallinity. Table II also shows $\Delta G^{\prime}$ values and $T_{\mathrm{g}} / T_{\mathrm{m}}$ of a commercial engineering plastic such as PBT and 4NT6 for comparison purposes. ${ }^{17}$ It is clear that PBT and 4NT6 have a good dimensional stability above $T_{\mathrm{g}}$. PASH-16 has a higher value of $\Delta G^{\prime}$ than
Table II. DMA results for PASHs and other thermoplastics

\begin{tabular}{|c|c|c|c|c|}
\hline Polymer Code & $T_{\mathrm{g}}\left({ }^{\circ} \mathrm{C}\right)$ & $\frac{G^{\prime} \text { at } 150^{\circ} \mathrm{C}}{\mathrm{MPa}}$ & $\Delta G^{\prime}$ & $T_{\mathrm{g}}(K) / T_{\mathrm{m}}(K)$ \\
\hline PASH-13 & 45 & 61 & 2.1 & 0.66 \\
\hline PASH-16 & 31 & 90 & 1.9 & 0.63 \\
\hline $4 \mathrm{NT}^{7}$ & 94 & 174 & 2.5 & 0.65 \\
\hline $\mathrm{PBT}^{17}$ & 50 & 79 & 5.6 & 0.65 \\
\hline
\end{tabular}

PBT, indicating that the dimensional stability above $T_{\mathrm{g}}$ is similar to PBT. Comparing with poly(alkylene terephthalate) such as PBT, PASH-13 and PASH-16 have a lower $T_{\mathrm{g}}$, which is ascribed to the longer flexible chains being present in the amorphous phase. In addition, PASH-13 and PASH-16 have 0.66 and 0.63 of the $T_{\mathrm{g}} / T_{\mathrm{m}}$, respectively. These values are nearly consistent with the $T_{\mathrm{g}} / T_{\mathrm{m}}$ ratio (2/3) for most semi-crystalline homopolymers. ${ }^{18,19}$

PASHs containing PEG ranging from 0 to $13 \mathrm{~mol} \%$ possess an extremely low strain since they are in the glassy state at ambient temperature. The tensile strength depends largely on the molecular weight of the polymer. Moreover, the ultimate tensile strength at application temperature can be considerably influenced by the position of glass transition temperature. The PASH-16 exhibits greatly improved the tensile strength among the PASHs series, comparable to the commercial thermoplastics. The stress at break of PASH-16 is approximately $60 \mathrm{MPa}$. PASHs containing $26 \mathrm{~mol} \%$ or more PEG were obtained as rubber-like materials at ambient temperature and have low stress and strain at break. These results imply that the control of $T_{\mathrm{g}}$ determine the mechanical properties and the intramolecular hydrogen bondings can be restricted by excess PEG.

\section{CONCLUSIONS}

Poly(oxyethylene-block-esteramide)s were synthesized with varying PEG content by bulk polymerization. $N, N^{\prime}$-Bis ( $p$-ethoxycarbonylphenyl) sebacamide inherently provided alternating arrangement of amide and ester groups, while PEG segments served as a chain extender and a reaction medium. The improved solubility of $N, N^{\prime}$-bis( $p$-ethoxycarbonylphenyl) sebacamide in the reaction mixture comprising PEG resulted in the increase of molecular weights. While the parent poly(ester-amide) was too brittle to give any measurable mechanical strength the poly(oxyethylene-blockesteramide) containing $16 \mathrm{~mol} \%$ of PEG formed flexible film with significant tensile strength. The DMA tests showed that poly(oxyethylene-block-esteramide)s containing $\sim 16 \mathrm{~mol} \%$ had high storage modulus at ambient temperature. The $T_{\mathrm{g}}$ appeared to decrease with increasing PEG, implying that the intramolecular hydro- 
gen bondings in amorphous phase might be restricted by excess PEG. From the spherulitic morphology and their WAXD curves, different kinds of spherulites and new crystalline peaks were observed with excess PEG (> $26 \mathrm{~mol} \%$ ), suggesting the amount of PEG accompanying with insignificant variations. PASH-16 presents a high $\Delta G^{\prime}$ similar to commercial engineering plastic, indicating that it has good dimensional stability above $T_{\mathrm{g}}$.

Acknowledgments. This work was supported by the Brain Korea 21 Project, the Basic Research program of the Korea Science \& Engineering Foundation (grant No. R01-1999-000-00194-0) and the Korea-Japan Basic Scientific Promotion Program (grant No. F01-2001000-20038-0).

\section{REFERENCES}

1. K. Bouma, G. de Wit, J. H. G. M. Lohmeijer, and R. J. Gaymans, Polymer, 41, 3965 (2000).

2. M. C. E. J. Niesten, J. Krijgsman, S. Harkema, and R. J. Gaymans, J. Appli. Polym. Sci., 82, 2194 (2001).

3. I. Goodman and A. Valavanidis, Eur. Polym. J., 20, 241 (1984).

4. V. D. Simone, G. Maglio, R. Palumbo, and V. Scardi, J. Appl. Polym. Sci., 46, 1813 (1992).
5. S. Y. Lee, J. W. Park, Y. T. Yoo, and S. S. Im, Polym. Degrad. Stab., 78, 63 (2002).

6. R. J. Gaymans and J. L. De Haan, Polymer, 34, 4360 (1993).

7. P. J. M. Serrano, E. Thuss, and R. J. Gaymans., Polymer, 38, 3893 (1997).

8. A. C. M. Van Bennekom and R. J. Gaymans, Polymer, 38, 657 (1997).

9. P. J. M. Serrano, B. A. Van de Werff, and R. J. Gaymans, Polymer, 39, 88 (1998).

10. M. C. E. J. Niesten, R. Tol, and R. J. Gaymans, Polymer, 42, 931 (2001).

11. S. J. Huang and S. H. Kim, Polym. Int., 46, 172 (1998).

12. H. M. Jeong, S. W. Moon, J. Y. Jho, and T. O. Ahn, Polymer, 39, 459 (1998).

13. E. Sorta and G. della Fortuna, Polymer, 21, 728 (1980).

14. Z. He and R. H. Olley, Polymer, 41, 1157 (2000).

15. A. Xenopoulos and E. S. Clark, in "Nylon Plastics Handbook", M. I. Kohan, Ed., Hanser-Gardner Publishers, Munich, Vienna, and New York, 1995, chapt. 5.

16. M. Takayuki "Dynamic Mechanical Analysis of Polymeric Material", Materials Science Monographs 1, Elsevier Northholland Inc., New York, NY, 1978, p 89.

17. P. J. M. Serrano, B. A. Van de Werff, and R. J. Gaymans, Polymer, 39, 83 (1998).

18. R. G. Beaman, J. Polym. Sci., 9, 472 (1953).

19. R. F. Boyer, Rubber Chem. Technol., 36, 1303 (1963). 